\title{
The determination of the repairs of railway track considering the reliability and risk level
}

\author{
Nikolai Kovalenko ${ }^{1 *}$, Elena Grin $^{1}$, and Nina Kovalenko ${ }^{1}$ \\ ${ }^{1}$ Russian University of Transport (MIIT), Obraztsova, 9, building 9, Moscow, 127994, Russia
}

\begin{abstract}
The method of predictive calculations of the state of the rails as the main element of assessing the state of the track when planning major repairs of the track is given. With a standard service life of 600 to 700 million tons gross, it is necessary to predict the number of defective rails on the track when increasing the service life to 1100 million tons gross (considering local rail replacement during intermediate repairs). The polygon for assigning repairs is determined by the number of "Windows" that can be provided per week on the section. The projected increase in the work of the track causes the need to increase life cycle cost depreciation charges for the formation of the repair Fund for capital repairs by $30-35 \%$.
\end{abstract}

\section{Introduction}

According to «The Strategy of the railway transport development in the Russian Federation up to 2030» and «The Development strategy of the JSC "RZD" up to 2030» (http://doc.rzd.ru/doc/public/ru?id=6396\&layer_id = 5104\& STRUCTURE_ID=704"), the program of the railway network development determines the main trends of the railway network reorganization in the planning, technology and organization of maintenance works.

On June 15, 2016, «The Regulation on the track facilities system of JSC "RZD», approved by the order of JSC "RZD" dated back 31.12.2015 No. 3212r (further, CVPX-2016), was introduced. In accordance with «The Instruction on the current maintenance of the railway track [Electronic resource]: approved by the order of JSC "RZD" dated back 14.11.2016 № 2288r Electronic Fund: site of legal and normative-technical documentation. Access mode: http://docs.cntd.ru/document/456052478", at present time CVPX-2016 determines the maintenance of a track due to the different operating conditions.

In February 2018, the Ministry of Transport of the Russian Federation amended the Rules of the railway operation in the territory of the Russian Federation (further, RRO), approved by the order No. 286 of the Ministry of Transport dated back December 21, 2010.

The order No. 54 of the Ministry of Transport dated back February 09, 2018 approved the revised version of the RRO. This document preserves the technological, organizational and technical parameters of the modern approaches to the track maintenance depending on different operating conditions.

The basis of modern planning of repair works is the assessment of the actual condition of a separate track element at a given time according to the results of its monitoring [1-3].

*Corresponding author: kni50@mail.ru 
When ranking and selecting the sections for the track repair works, the standards of technical operation «STO RZD 02.041-2011 Management of resources, risks and reliability at the stages of the life cycle (URRAN RAMS). Systems, devices and equipment of track facilities. Requirements for the reliability and functional safety» regulate the application procedure and rules of the total assessment indicators: reliability, risk level and its reduction, track operating time, the probability of a partial or complete failure [4 -6].

\section{Materials and Methods}

The application of the URRAN methodology, which is considered in CVPX-2016, is an attempt to consider the risk level of a failure probability $(\lambda)$ of technical means during their operation [7, 8].

According to «The Guidelines for calculating of the economic efficiency of new equipments, technology, intellectual property and innovation proposals: order No. 2538r of JSC «RZD» dated back 28.11.2008», the assessment using the methodology of the URANIUM RAMS does not provide any decision-making system. The criteria of the URRAN RAMS methodology are of advisory nature [9-12].

To consider the modern trends which forecast the operational period of track sections, the authors $[13,14]$, propose to introduce an index of the given repair works volumes during the overhaul (between overall repair works) period of the track section operation $\left(Q_{\text {prived }}^{\mathrm{GL}}\right)$

\section{Results}

It is proposed to take into account the indices of reliability and risk levels of the track infrastructure by applying the technical condition coefficient $\left(\boldsymbol{k}_{\boldsymbol{t} \text { ex } V \boldsymbol{C P} \boldsymbol{P}}\right)$ of the permanent way structure and the infrastructure for the track sections $\left(Q_{\text {peregon }}^{G L}\right)$ (Formula 1):

$$
Q_{\text {prived }}^{\mathrm{GL}}=k_{\text {texVCP }} \cdot Q_{\text {peregon }}^{\mathrm{GL}}
$$

The overhaul period is divided into 5 subgroups for which the values of the technical condition coefficient of $\left(\boldsymbol{k}_{\text {tex } \boldsymbol{V} \boldsymbol{C P})}\right)$ are determined (Table 1), in order to harmonize the overhaul period of the track operation according to the passed tonnage.

In accordance with the «Methods of expenditure planning for the current operation of the railway tracks and structures due to the classification of the railway lines: approved by the order No. 1692r of JSC "RZD" dated back 21.08.2017», planning of the track repair works volumes by taking into account the reliability and risk levels indices, dealing with track elements and the whole technical means of the track, is the basis to make management decisions for planning of repair works or the current maintenance of the track $[13,14]$.

Table 1. The values of the technical condition coefficient for the permanent way structure and the track infrastructure $\left(\boldsymbol{k}_{\text {tex } V C P}\right)$, which considers the reliability and risk levels of the track infrastructure when calculating the indices of the given volumes of the track repair works.

\begin{tabular}{|l|l|l|l|}
\hline Subgroup & $\begin{array}{l}\text { The range of changes in the past } \\
\text { tonnage on a track section }\end{array}$ & $\begin{array}{l}\text { Values of the } \\
\text { coefficient } \boldsymbol{k}_{\text {tex } V C \boldsymbol{P}}\end{array}$ & Notes \\
\hline A & from 0 to $0.25 \cdot\left|\mathbf{T}_{\mathbf{0}}\right|$ & 1.10 & \multirow{3}{*}{ for the experimental application } \\
\hline B & from $0.25 \cdot\left|\mathbf{T}_{\mathbf{0}}\right|$ to $0.50 \cdot\left|\mathbf{T}_{\mathbf{0}}\right|$ & 1.00 & \\
\hline $\mathrm{C}$ & from $0.50 \cdot\left|\mathbf{T}_{\mathbf{0}}\right|$ to $0.75 \cdot\left|\mathbf{T}_{\mathbf{0}}\right|$ & 1.15 & \\
\hline $\mathrm{D}$ & from $0.75 \cdot\left|\mathbf{T}_{\mathbf{0}}\right|$ to $\left|\mathbf{T}_{\mathbf{0}}\right|$ & 1.20 & \\
\hline $\mathrm{G}$ & more than $\left|\mathbf{T}_{\mathbf{0}}\right|$ & 1.35 & \\
\hline
\end{tabular}

Notes to Table 1:

1 The values of the coefficients $\boldsymbol{k}_{\text {tex } \boldsymbol{V} \boldsymbol{C} \boldsymbol{P}}$ were obtained from the permanent way survey done by the Kuibyshev Infrastructure Directorate and the permanent way survey done by the 
South Ural Infrastructure Directorate.

2 The application of the obtained values $\boldsymbol{k}_{\boldsymbol{t} \text { ex } V \boldsymbol{C} \boldsymbol{P}}$ can be recommended for the conditions of the geographical setting and the operational parameters similar to the permanent ways of the Kuibyshev Infrastructure Directorate and the permanent ways of the South Ural Infrastructure Directorate.

3 The coefficient $\boldsymbol{k}_{\text {texVCP}}$ can be applied in an experimental way only to calculate the indices of the given volumes of track repair works.

$4\left|\mathrm{~T}_{\mathrm{o}}\right|$ - an average network standard of the passed tonnage before carrying out the reconstruction (modernization) or the overall repair works of the track, determined by the regulations CVPX-2016 in dependence to the class of a line and the track, a group, a category and track specialization.

The demanded time for the period $\left(\boldsymbol{T}_{\boldsymbol{p} e r}\right)$ of overall, average track repair works with deep cleaning of the ballast $(40 \div 50 \mathrm{~cm}$ below the sleeper toes) and other works is calculated by Formula 2.

where:

$$
\begin{gathered}
\mathrm{T}_{\mathrm{per}}=\frac{\left(1-R_{n a d}\right) \cdot Q_{\text {prived }}^{G L}}{4 \cdot n_{m} \cdot l_{a}}, \quad \text { months, } \\
R_{\text {nad }}=1-\frac{N_{. e l}^{o t k}}{N_{\text {км }} \cdot n_{i}}
\end{gathered}
$$

$N_{. e l}^{o t k}$ - the number of element (rails, sleepers and fastenings) failure on the length of the subgroup (Table 1) within the whole section being considered in a year per items;

$N_{\kappa M}$ - the number of kilometers in the track section subgroup in a year;

$n_{i}$ - the number of inspections of an $i$-element condition in a year;

$R_{\text {nad }}$ - the reliability index, determined for each track section subgroup on a train-section per a track element;

$Q_{\text {prived }}^{G L}$ the annual planned volume of track repair works on a train-section, km;

$\boldsymbol{n}_{\boldsymbol{m}}$ - the number of «breaks», that can be provided in a week in dependence to the intensity of the train-handling capacity;

$\boldsymbol{l}_{\boldsymbol{a}}$ - the estimated output standard of the contractor during the «break», km;

4 - the number of weeks in a month.

If 3 or more «breaks» can be provided in a week due to the low intensity of the trainhandling capacity, then when calculating the duration of the repair works period, the number of «breaks» depends on the established organization and technology of works.

When the required duration of the track repair works, calculated by Formula 2, exceeds the season or violates the terms established by JSC "RZD", the several track maintenance trains (further - TMT) operate simultaneously.

The number of TMTs which are to operate simultaneously on a train-section, is determined according to the target volume of repair works, terms of performance and the number of «breaks», provided in a week.

The overall repair works with the use of new and old materials, the average repair works with deep cleaning on two-track (multi-track) lines, as a rule, should be carried out on the sections which are closed for train traffic for $6 \div 10$ days.

The required time to carry out the planned volume of repair works with the train traffic congestion is determined on the limiting machine (for example, a ballast cleaning one) according to Formula 4:

where,

$$
\begin{gathered}
\mathrm{T}_{\mathrm{per}}=\frac{I_{\text {def.el }} \cdot \boldsymbol{Q}_{\text {prived }}^{G L}}{l_{F C H} \cdot t_{m}} \\
I_{\text {def.el. }}=\frac{N_{\text {def.el. }}^{\text {povgd }}}{G n}
\end{gathered}
$$


$I_{\text {def.el. }}$ - the intensity of accumulation of defective elements (rails, defective sections in the ballast layer, sleepers and fastenings) in the subgroup (Table1), items $/ \mathrm{mln}$.t gross weight in a year;

$l_{F C H}$ - the estimated output standard of a ballast cleaning machine $(\mathrm{km} / \mathrm{h})$;

$N_{\text {.el }}^{\text {povrgd }}$ - the number of element (rails, sleepers and fastenings) failures on the track length belonging to the subgroup (Table 1) within the whole length of the section in a year, items;

$\mathrm{Gn}$ - the density of train traffic on a section in the subgroup, mln. $\mathrm{t} \cdot \mathrm{km}$ gfoss weight $/ \mathrm{km}$ in a year;

$t_{m}$ - the operational time of a ballast cleaning machine in a day (h/days).

To achieve the standard operation time (up to $1 \div 1.1$ billion $t$ of gross weight) of the continuous welded track, a system of a targeted restoration of track elements (in particular, rails) is demanded (Table 3$)$ [15, 16, 17].

The percentage of the continuously welded rail defect is taken as the main criterion of the appointment of the overall repair works or the rail replacement on the continuous welded track. The percentage of the continuously welded rail defect is referred to $1 \mathrm{~km}$ of a track during the whole operational period of the continuously welded rail, without taking into consideration the defects in equalizing spans or lateral wear of the rail head (code 44). The percentage of the continuously welded rail defect is recommended to be set at the level of $3 \div 5 \%$ depending on the class of the track.

\section{Discussion}

Task: Due to the established standard service life of $600 \div 700 \mathrm{mln}$. tons of gross weight [13, $14]$ it is required to carry out quantity forecasting of the defective rails on a track when the service life increases up to $1100 \mathrm{mln}$. tons of gross weight (considering the local rail replacement when carrying out the overhaul repair works).

When forecasting the operation time of tonnage $\left(\boldsymbol{Q}_{\text {progn }}\right)$ for the established 5 ranges of track section subgroups aimed at the change of the passed tonnage on the section (Table 2) with the use of Lagrange polynomials, the calculation formula will have the following, Formula 6:

$$
Q_{\text {progn }}(t)=\sqrt{\frac{\left[-5 X\left(t_{1}\right)+6 X\left(t_{2}\right)\right]^{2}}{2}+\frac{\left[15 X\left(t_{1}\right)-35 X\left(t_{2}\right)+21 X\left(t_{3}\right)\right]^{2}}{2}}
$$

On the basis of the statistical processing of the facts describing rail failures on the sections of the permanent way of the Kuibyshev Infrastructure Directorate the following data were retrieved (Table 2):

Table 2. The forecasted number of the defective rails in items per $1 \mathrm{~km}$ with the progressive total (the example for the conditions on the permanent way of the Kuibyshev Infrastructure Directorate)

\begin{tabular}{|l|l|}
\hline $\begin{array}{l}\text { Average service life }\left(\boldsymbol{T}_{\boldsymbol{o}}\right), \\
\text { mln. t gross weight }\end{array}$ & The estimated number of defective rails, items per 1 km \\
\cline { 2 - 2 } & (on the example of permanent way of the Kuibyshev Infrastructure Directorate) \\
\hline $\boldsymbol{X}\left(\boldsymbol{t}_{1}\right)=570$ & 2.6 \\
\hline $\boldsymbol{X}\left(\boldsymbol{t}_{2}\right)=680$ & 4.7 \\
\hline $\boldsymbol{X}\left(\boldsymbol{t}_{3}\right)=790$ & 5.2 \\
\hline $\boldsymbol{X}\left(\boldsymbol{t}_{\text {prognoz }}\right)>900$ & 15.7 (the forecast due to Formula 6) \\
\hline
\end{tabular}

The calculation results for the forecasting task:

Forecast calculations at operation time of $1100 \mathrm{mln} . \mathrm{t} \cdot \mathrm{km}$ gross weight with the application of using Lagrange polynomials have resulted in the following calculated values of the rail failures: 


$$
Q_{\text {progn }}(t)=\sqrt{\frac{[-5 \times 2.6+6 \times 4.7]^{2}}{2}+\frac{[15 \times 2.6-35 \times 4.7+21 \times 5.2]^{2}}{2}}=15.7 \quad \text { item } / \mathrm{km}
$$

Practical recommendations: for each track section in accordance with the index of its reliability and risk level, the Head of the Technical Department of the permanent way together with the engineer on the organization and regulation of labor prepare an inventory of planning of track repair works in the form of Table 3.

\section{Conclusions:}

It has been developed the method of forecasting calculations of the operating condition of the permanent way (and rails and as a basic element of the assessment of a track condition) used for planning of the overall repair works, as well as the overall repair works or rail replacement on the continuous welded track. The results of the forecasting calculations presented in the table should be considered from several points of view:

- the increase in transportation volumes more than the established standard values (according to Rules of the technical operation of the railways in the Russian Federation, approved by the Order No. 54 of the Ministry of Transport of the Russian Federation dated back February 09, 2018), causes the demand in the increase in the repair works volumes to keep the necessary working characteristics of the track structure. This increase is represented by the use of the coefficients $\boldsymbol{k}_{\text {tex } V \boldsymbol{C} \boldsymbol{P}}$ which are more than one;

- the forecasted growth of transportation volumes that exceed the standard values leads to the increase in depreciation charges for the formation of the overall repair works fund. In Table 3 this increase is also represented by the use of the coefficients $\boldsymbol{k}_{\operatorname{tex} V \boldsymbol{C} \boldsymbol{P}}$ which are more than one;

- the increase in the volume of works in the range immediately after the overall repair works, caused by the stabilization of the track elements, in Table 3 is also represented by the use of the coefficients $\boldsymbol{k}_{\text {tex } V C \boldsymbol{P}}$ which are more than one.

As an example of calculating the need for track work using the developed methodology, the following sections of railway track and their characteristics are considered in table 3 .

Table 3. List and characteristics of railway track and their sections.

\begin{tabular}{|c|c|c|c|c|c|c|c|c|}
\hline \multirow[b]{2}{*}{ 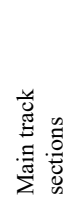 } & \multirow{2}{*}{ 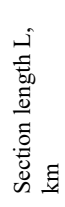 } & \multirow{2}{*}{ 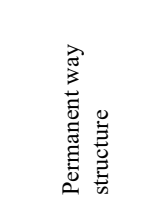 } & \multirow{2}{*}{ 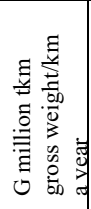 } & \multirow{2}{*}{ 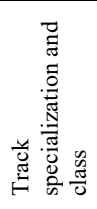 } & \multirow[b]{2}{*}{$f_{i}$} & \multicolumn{2}{|c|}{ Standard frequency for $\mathrm{K}_{\mathrm{H}}$ or $\mathrm{K}_{\mathrm{C}}$} & \multirow[b]{2}{*}{$\begin{array}{l}\text { Track work in the } \\
\text { period } K_{H}\left(\text { or } K_{C}\right)\end{array}$} \\
\hline & & & & & & $\begin{array}{l}\text { T, million t. } \\
\text { gross weight. }\end{array}$ & $\begin{array}{l}\mathrm{N}=\mathrm{T} / \mathrm{Gn}, \\
\text { years }\end{array}$ & \\
\hline 1 & 2 & 3 & 4 & 5 & 6 & 7 & 8 & 9 \\
\hline A-D & 56 & \multirow{4}{*}{$\begin{array}{l}\text { Continuous } \\
\text { welded track; } \\
\text { rails P65; } \\
\text { ballast crashed } \\
\text { stone }\end{array}$} & 35 & Ps2V3 & $0,9^{1}$ & $1100 \times 0,9=990$ & $990 / 35=28$ & $\left(\mathrm{~K}_{\mathrm{H}}\right) \mathrm{BCBB}\left(\mathrm{K}_{\mathrm{H}}\right)$ \\
\hline $\mathrm{D}-\mathrm{A}$ & 56 & & 40 & Ps2V3 & $0,9^{1}$ & $1100 \times 0,9=990$ & $990 / 40 \approx 25$ & $\left(\mathrm{~K}_{\mathrm{H}}\right) \mathrm{BCBB}\left(\mathrm{K}_{\mathrm{H}}\right)$ \\
\hline E-F & 44 & & 50 & Gr2V3 & $0,9^{2}$ & $1100 \times 0,9=990$ & $990 / 50 \approx 20$ & $\left(\mathrm{~K}_{\mathrm{H}}\right) \mathrm{BCBB}\left(\mathrm{K}_{\mathrm{H}}\right)$ \\
\hline F-E & 44 & & 60 & Gr1B3 & $0,9^{3}$ & $1100 \times 0,9=990$ & $990 / 60 \approx 16,5$ & $\left(\mathrm{~K}_{\mathrm{H}}\right) \mathrm{BCB}\left(\mathrm{K}_{\mathrm{H}}\right)$ \\
\hline N-M & 23 & \multirow{2}{*}{$\begin{array}{l}\text { A jointed track, } \\
\text { P65, crashed } \\
\text { stone. }\end{array}$} & 26 & Gr2V3 & $0,9^{4}$ & $600 \times 0,9=540$ & $540 / 26 \approx 21$ & $\left(\mathrm{~K}_{\mathrm{H}}\right) \mathrm{BCBB}\left(\mathrm{K}_{\mathrm{H}}\right)$ \\
\hline $\mathrm{M}-\mathrm{N}$ & 40 & & 15 & Gr3G4 & & 270 & $270 / 15 \approx 18$ & $\mathrm{~K}_{\mathrm{HBC}} \Pi_{\mathrm{C}}$ \\
\hline Total & 263 & & & & & & & \\
\hline
\end{tabular}


Table 4. The classification of the permanent ways and the calculated demand for the track work on the sections considering the reliability and risk levels

\begin{tabular}{|c|c|c|c|c|c|c|c|}
\hline \multirow{2}{*}{$\begin{array}{l}\text { Main } \\
\text { track } \\
\text { sections }\end{array}$} & \multirow{2}{*}{$\begin{array}{l}\text { The range of } \\
\text { changes in the past } \\
\text { tonnage on a } \\
\text { section }\end{array}$} & \multirow{2}{*}{$\begin{array}{l}\text { Coefficient } \\
\text { of } \\
\text { reliability } \\
\text { and risk } \\
\text { levels } \\
\left(\boldsymbol{k}_{\text {tex } V C P}\right)\end{array}$} & \multicolumn{5}{|c|}{$\begin{array}{l}\text { The estimated annual demand for track work } \\
\text { considering the reliability and risk levels }\end{array}$} \\
\hline & & & $\mathrm{K}_{\mathrm{H}}$ & $\mathrm{K}_{\mathrm{C}}$ & $\mathrm{C}$ & $\mathrm{P}$ & B \\
\hline 1 & 10 & 11 & 12 & 13 & 14 & 15 & 16 \\
\hline \multirow{5}{*}{ A-D } & 0 to $0.25\left|T_{0}\right|$ & 1.10 & & & & & \\
\hline & $0.25\left|\mathrm{~T}_{\mathrm{o}}\right|$ to $0.50\left|\mathrm{~T}_{\mathrm{o}}\right|$ & 1.00 & & & & & 2.0 \\
\hline & $0.50\left|\mathrm{~T}_{\mathrm{o}}\right|$ to $0.75\left|\mathrm{~T}_{\mathrm{o}}\right|$ & 1.15 & & & 2.3 & & \\
\hline & $0.75 \cdot\left|\mathrm{T}_{\mathrm{o}}\right|$ to $\left|\mathrm{T}_{\mathrm{o}}\right|$ & 1.20 & & & & & 4.8 \\
\hline & $\left|\mathrm{T}_{\mathrm{o}}\right|$ and more & 1.35 & 2.7 & - & & & \\
\hline \multirow{5}{*}{ D-A } & 0 to $0.25\left|\mathrm{~T}_{\mathrm{o}}\right|$ & 1.10 & & & & & \\
\hline & $0.25\left|\mathrm{~T}_{\mathrm{o}}\right|$ to $0.50\left|\mathrm{~T}_{\mathrm{o}}\right|$ & 1.00 & & & & & 2.24 \\
\hline & $0.50\left|\mathrm{~T}_{\mathrm{o}}\right|$ to $0.75\left|\mathrm{~T}_{\mathrm{o}}\right|$ & 1.15 & & & 2.576 & & \\
\hline & $0.75 \cdot\left|\mathrm{T}_{\mathrm{o}}\right|$ to $\left|\mathrm{T}_{\mathrm{o}}\right|$ & 1.20 & & & & & 5.376 \\
\hline & $\left|\mathrm{T}_{\mathrm{o}}\right|$ and more & 1.35 & 3.024 & - & & & \\
\hline \multirow{5}{*}{ E-F } & 0 to $0.25\left|\mathrm{~T}_{\mathrm{o}}\right|$ & 1.10 & & & & & \\
\hline & $0.25\left|\mathrm{~T}_{\mathrm{o}}\right|$ to $0.50\left|\mathrm{~T}_{\mathrm{o}}\right|$ & 1.00 & & & & & 2.42 \\
\hline & $0.50\left|\mathrm{~T}_{\mathrm{o}}\right|$ to $0.75\left|\mathrm{~T}_{\mathrm{o}}\right|$ & 1.15 & & & 2.53 & & \\
\hline & $0.75 \cdot\left|\mathrm{T}_{\mathrm{o}}\right|$ to $\left|\mathrm{T}_{\mathrm{o}}\right|$ & 1.20 & & & & & 5.28 \\
\hline & $\left|\mathrm{T}_{0}\right|$ and more & 1.35 & 2.97 & - & & & \\
\hline \multirow{5}{*}{ F-E } & 0 to $0.25\left|\mathrm{~T}_{\mathrm{o}}\right|$ & 1.10 & & & & & \\
\hline & $0.25\left|\mathrm{~T}_{\mathrm{o}}\right|$ to $0.50\left|\mathrm{~T}_{\mathrm{o}}\right|$ & 1.00 & & & & & 2.7 \\
\hline & $0.50\left|\mathrm{~T}_{\mathrm{o}}\right|$ to $0.75\left|\mathrm{~T}_{\mathrm{o}}\right|$ & 1.15 & & & 3.105 & & \\
\hline & $0.75 \cdot\left|\mathrm{T}_{\mathrm{o}}\right|$ to $\left|\mathrm{T}_{\mathrm{o}}\right|$ & 1.20 & & & & & 3.24 \\
\hline & $\left|\mathrm{T}_{\mathrm{o}}\right|$ and more & 1.35 & 3.645 & - & & & \\
\hline \multirow{5}{*}{$\mathrm{N}-\mathrm{M}$} & 0 to $0.25\left|\mathrm{~T}_{\mathrm{o}}\right|$ & 1.10 & & & & & \\
\hline & $0.25\left|\mathrm{~T}_{\mathrm{o}}\right|$ to $0.50\left|\mathrm{~T}_{\mathrm{o}}\right|$ & 1.00 & & & & & 1.27 \\
\hline & $0.50\left|\mathrm{~T}_{\mathrm{o}}\right|$ to $0.75\left|\mathrm{~T}_{\mathrm{o}}\right|$ & 1.15 & & & 1.46 & & \\
\hline & $0.75 \cdot\left|\mathrm{T}_{\mathrm{o}}\right|$ to $\left|\mathrm{T}_{\mathrm{o}}\right|$ & 1.20 & & & & & 3.048 \\
\hline & $\left|T_{0}\right|$ and more & 1.35 & 1.715 & - & & & \\
\hline \multirow{5}{*}{ M-N } & 0 to $0.25\left|T_{0}\right|$ & 1.10 & & & & & \\
\hline & $0.25\left|\mathrm{~T}_{\mathrm{o}}\right|$ to $0.50\left|\mathrm{~T}_{\mathrm{o}}\right|$ & 1.00 & & & & & 2.66 \\
\hline & $0.50\left|\mathrm{~T}_{\mathrm{o}}\right|$ to $0.75\left|\mathrm{~T}_{\mathrm{o}}\right|$ & 1.15 & & & 3.059 & & \\
\hline & $0.75 \cdot\left|\mathrm{T}_{\mathrm{o}}\right|$ to $\left|\mathrm{T}_{\mathrm{o}}\right|$ & 1.20 & & & & 3.192 & \\
\hline & $\left|T_{0}\right|$ and more & 1.35 & - & 3.591 & & & \\
\hline Total & & & $\begin{array}{l}14.054 \\
(+32 \%)\end{array}$ & $\begin{array}{l}3.591 \\
(+35 \%)\end{array}$ & $\begin{array}{l}18.089 \\
(+18 \%)\end{array}$ & $\begin{array}{l}3.192 \\
(+12 \%)\end{array}$ & $\begin{array}{l}40.886 \\
(+11 \%)\end{array}$ \\
\hline
\end{tabular}

Notes to Table 3, 4:

1) in Column 11 the values of the coefficient of reliability and risk levels $\left(\boldsymbol{k}_{\text {tex } V C P}\right)$ are chosen due to the range of the elimination and prevention of the most complicated and easily damaged track sections which are the most hazardous to the safe train traffic;

2) in Column 7: the coefficient $f_{i}$ - characterizes the decrease in the standard track maintenance:

${ }^{1}$ - the decrease in the standard is caused by the average length of the continuously welded rails which is shorter than the standard one;

${ }^{2}$ - the decrease in the standard is caused by the insufficient thickness of the crashed stones on the sections;

3 - the decrease in the standard is caused by the absence of wheel grinding;

4 - the decrease in the standard is caused by the proximity of coal shipping areas;

3) in Column 9 the denotations of the repair works are presented:

- $\mathrm{K}_{\mathrm{H}^{-}}$the overall repair work with the use of new materials (the overall repair work of Level I); 
- $\mathrm{C}$ - the average repair work of a track;

- $\mathrm{P}$ - the track raising repair work;

- $\mathrm{K}_{\mathrm{C}}$ - the overall repair work with the help of used materials (the overall repair work of Level II);

- B - the system repairs of a track;

4) in Column 5 the denotations of the track classification and specialization are presented:

- Ps - primary passenger train traffic;

- Gr - primary freight train traffic;

- V, G, B - the group of tracks characterized by the density of traffic Gn - Column 4;

5) in the brackets of Column «Total» the increase in the volumes of the repair works relying on the coefficient $\boldsymbol{k}_{\text {tex } V \text { CP.. }}$ is presented.

\section{References}

1. D. Milne, L. Le Pen, G. Watson et al., Transportation Geotechnics, 17, 61-68 (2018).

2. Y. Zhang, A. D'Ariano, B. He, Q. Peng. Transportation Research Part B: Methodological, 127, 237-278 (2019).

3. H. Wen, S. Hou, Z. Liu, Y. Liu. Chaos, Solitons \& Fractals, 105, 69-76 (2017).

4. Z. Su, A. Jamshidi, A. Núñez et al., Transportation Research Part C: Emerging Technologies, 105, 359-384 (2019).

5. T. Lidén. Transportation Research Procedia, 10, 574-583 (2015).

6. A. D'Ariano, L. Meng, G. Centulio, F. Corman. Computers \& Industrial Engineering, 127, 1315-1335 (2019).

7. İ. Şahin. Journal of Rail Transport Planning \& Management, 7(3), 101-113 (2017).

8. I. Durazo-Cardenas, A. Starr, C.J. Turner et al., Transportation Research Part C: Emerging Technologies, 89, 234-253 (2018).

9. K. Adjetey-Bahun, B. Birregah, E. Châtelet, J.-L. Planchet. Reliability Engineering \& System Safety, 153, 1-14 (2016).

10. B. de Jonge, P. A. Scarf. European Journal of Operational Research, In press, corrected proof, Available online 26 (2019).

11. T. Chiang, H.Y. Hau et al., Data \& Knowledge Engineering, 27(3/1), 289-312 (1998).

12. T. Dewilde, P. Sels, D. Cattrysse, P. Vansteenwegen. Journal of Rail Transport Planning \& Management, 3(3), 68-77 (2013).

13. B. Volkov, N. Kovalenko et al., J. Path and track facilities, 6, 13-18 (2019).

14. B. Volkov, N. Kovalenko et al., J. Path and track facilities, 5, 23-26 (2018).

15. T.L. Norman. Electronic Access Control (Second Edition), 519-535 (2017).

16. V. Tsvetkov European Journal of Economic Studies, 1, 45-50 (2012).

17. M. Hartong, R. Goel, D. Wijesekera. Journal of King Saud University - Science, 23(3), 311-321 (2011). 